\title{
Review
}

Sahar Idris, Anuradha Mishra* and Mohd Khushtar

\section{Phytochemical, ethanomedicinal and pharmacological applications of escin from Aesculus hippocastanum L. towards future medicine}

https://doi.org/10.1515/jbcpp-2019-0115

Received July 31, 2019; accepted March 19, 2020; published online July 11,2020

\begin{abstract}
Medicinal plants are used from ancient times for treatment of various ailments. Aesculus hippocastanum (Horse chestnut), is the popular and most valuable tree native to the South East Europe. It's seed extracts and their concentrates contain phytocompounds like flavonoids, polyphenols, triterpenoid saponin glycosides (escin), epicatechin, tannins, kaempferol, esculin, fraxin, carbohydrate, essential fatty acids (linoleic acid), oleic acid and purine bases (adenine and guanine). Due to these vital phyto-constituents, horse chestnut is used in phytomedicine for the prevention and treatment of diverse disorders as in venous congestion in leg ulcers, bruises, arthritis, rheumatism, diarrhoea, phlebitis etc. We collected the pharmacological applications of Aesculus hippocastanum L. extracts and escin as the cheif bioactive compound and their uses in traditionally and clinically for the management of various disorders. This review describes the efficacy of $A$. hippocastanum $\mathrm{L}$. extracts and their bioactive compounds. So in the furtue this plant may be useful for the alternative treatment measure for various ailments via incorporating either extract or escin into novel delivery systems for improving the social health in future and would provide improved quality of life.
\end{abstract}

Keywords: Aesculus hippocastanum; bioactive compound; escin; pharmacological properties.

\footnotetext{
*Corresponding author: Dr. Anuradha Mishra, Associate Professor, Faculty of Pharmacy, Integral University, Lucknow, Uttar Pradesh, India, Mobile: +91 7376550091, E-mail: misra.anuradha@gmail.com. https://orcid.org/0000-0002-2675-3479

Sahar Idris and Mohd Khushtar: Faculty of Pharmacy, Integral University, Lucknow, Uttar Pradesh, India
}

\section{Introduction}

According to WHO (world health organization) about $80 \%$ population utilize only traditional medication for the treatment of various ailments or as health promoting agent. Chief bioactive constituents or whole plants are used for the preparation of herbal extract or medicine which may utilize for the different purpose [1]. Plants are the important part of green urban and rural areas with many positive economic, social, and climatic effects [2, 3]. Plants are the valuable source of natural products such as fruits, bark, leaves, stems, wood, food, dietary supplements, cosmetic and most important herbal medicines [4]. Phytotherapy is considered owing to their minimal or no side effect as reported by scientist for Pyrozolidine alkaloids presenting plant extracts, when evaluated for any potential toxicity at $250 \mathrm{mg} / \mathrm{kg}$ for 28 days didn't show any toxicity in compared to Pyrazolodine molecule. Further herbal bioactives are cost-effective for any therapy in compared to Allopathic medications as they are much expensive and have higher toxicity risks $[5,6,73]$. Aesculus hippocastanum L. commonly known as horse chestnut and buckeyes [7], is a rapidly growing ornamental tree belonging to the family hippocastanaceae, used for the prevention of many diseases and highly adapted in polluted environment [8]. Trees are grown up to $30 \mathrm{~m}$ in height and $1 \mathrm{~m}$ thick with short stem having a rounded crown [9]. Escin is a chief bioactive compound of horse chestnut seed, which is chemically related to triterpenic glycoside. Seed cotyledons are the main source of escin, but small quantity is also found in leaves, bark and immature fruit pericarp [10]. Escin has different pharmacological activities such as anti-inflammatory, vasoprotective in chronic venous insufficiency. On the basis of scientific research about 20 individual compounds have been identified including escin out of which the most active component is escin Ia, due to their role as antidiabetic, anti-inflammatory and gastroprotective [11]. The 
Table 1: Phytoconstituents with their chemical structures.

S.No. Chemical constituent
Fraxetin

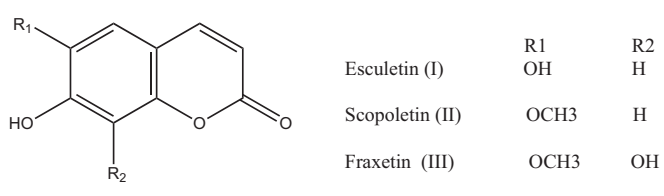

Structure of esculetin, scopoletin and fraxetin

- Escin la

4

5 Isoescin la (alpha)

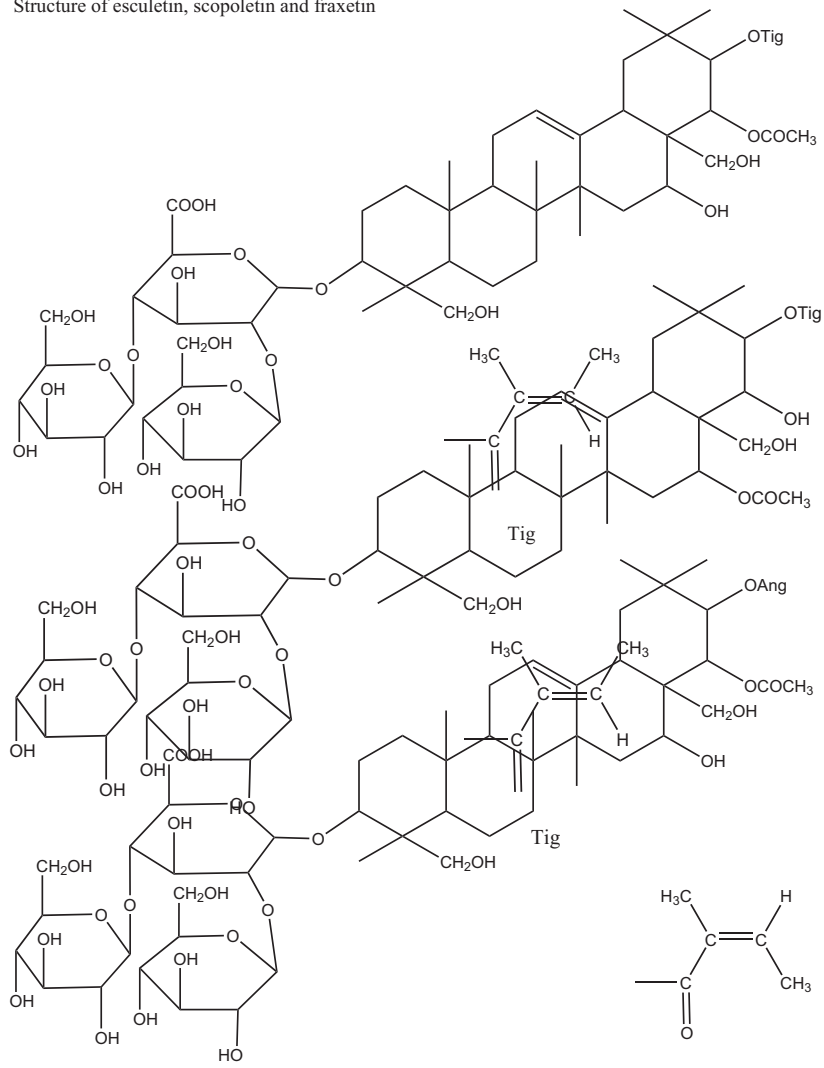

Ang 
Table 2: Active phytoconstituent and their pharmacological activities.

\begin{tabular}{llll}
\hline $\begin{array}{c}\text { S.No. Active } \\
\text { constituent }\end{array}$ & Pharmacological activities & References \\
\hline 1 & Aescin & $\begin{array}{c}\text { Anti-inflammatory, anti-edametous, } \\
\text { anti-secretory, anti-oxidative, veno- } \\
\text { tonic activity }\end{array}$ & {$[24,44]$} \\
2 & Esculin & $\begin{array}{l}\text { Used for treatment of CVI, burn skin } \\
\text { inflammation and hemorhoids }\end{array}$ \\
3 & Flavonoids & $\begin{array}{l}\text { Radical scavining, antiviral, antibac- } \\
\text { terial activity and used in capillary } \\
\text { fragility }\end{array}$ \\
\hline
\end{tabular}

leaves of the plants are attacked by leaf mining insect Cameraria ohridella which is known as horse chestnut leaf-miner [12]. The main host of the leaf miner is white flowering horse chestnut (Aesculus hippocastanum L.) but caterpillars of this species have also been observed on other trees of the same genus [13]. The larvae of the moth feed on the leaf parynchyma. Some time whole leaf is infected and get brown, dry up and fall off while, margins of the leaf blade were fold-in [14]. The Cameraria ohridella minig affects the quality of seeds but has no effect on the quantity of seed [15]. There are some discriminating methods to prevent the plant from pests by the segregation of leaves of the plants, microinjection of a special gel (endotherapy), large sticky traps placed on tree trunks, pheromone traps, soil injections but these are very expensive and harmful for human, so parasitoids are the natural enemies of leafminer [16]. Around 100 varieties or species of Aesculus have been discovered and from them 210 compounds were isolated from the seeds are of different classes [17].

\section{Phytoconstituents}

The most valuable constituents of Aesculus hippocastanum seed extract are escin and prosapogenin. Escin is a group of triterpenoid saponin glycoside including glycosides of protoaescigenin barringtogenol C [7]. Escin is categorized into two classes $\alpha$ - and $\beta$-escin and they can be differentiated on the basis of its melting point, hemolytic index, solubility in water and by specific rotation [18]. Leaf extracts are rich in carbohydrate and anthocyanin [19]. Flowers contain coumarin such as esculin, esculetin, scopoletin and fraxetin. Esculetin, scopoletin and fraxetin are inhibitors of the proinflammatory lipoxygenase (LOX) and cyclooxygenase (COX) pathways of arachidonate metabolism, thus, act as an anti-inflammatory agent. A. hippocastanum also contains flavonoids, tannins, amines, amino acids, uric acid, phytosterol, resins, citric acid epicatechin, leucocyanidine, fatty acids such as oleic and linoleic acid [20-22], kaempferol derivative like kaempferol: 3-O- $\alpha$-arabinofuranoside, 3-O- $\beta$-glucopyranoside,

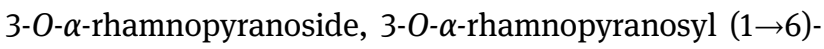
0 - $\beta$ - glucopyranoside and quercetin: 3-O- $\alpha$-arabinofuranoside, 3-O- $\beta$-glucopyranoside, 3-O- $\alpha$-rhamnopyranosyl $(1 \rightarrow 6)-0-\beta$-glucopyranoside [23]. The chemical structures of phytoconstituents present in horse chestnut are shown in Table 1.

Various research results confirmed that Aesculus hippocastanum and its bioactive compound possess different pharmacological properties which are as shown in Table 2

\section{Traditional uses}

In folk medicine, $A$. hippocastanum extract and their preparations are applied for the management of peripheral and vascular disorders like varicose veins, venous and hematoma [17, 24], cardiac venous insufficiency, hemorrhoids, pain, swelling and heaviness of lower limb [25], burns, epidermis abrasion, diarrhoea, phlebitis, fever and for the treatment of enlargement of prostate gland [26, 27]. In China, Beta-escin is traditionally used as for flatulence, anorexia,

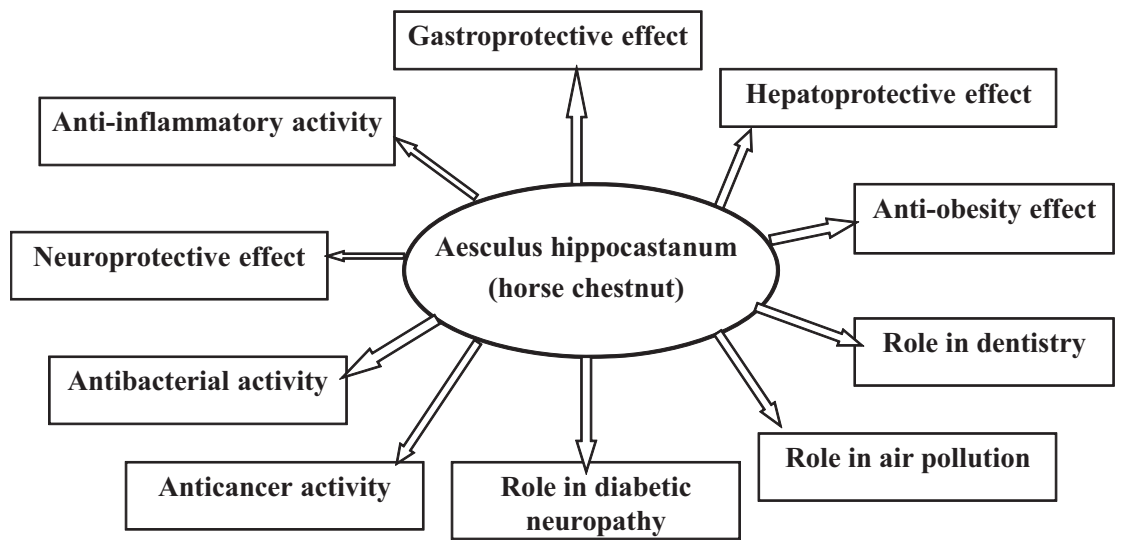

Figure 1: Specific pharmacological effects. 


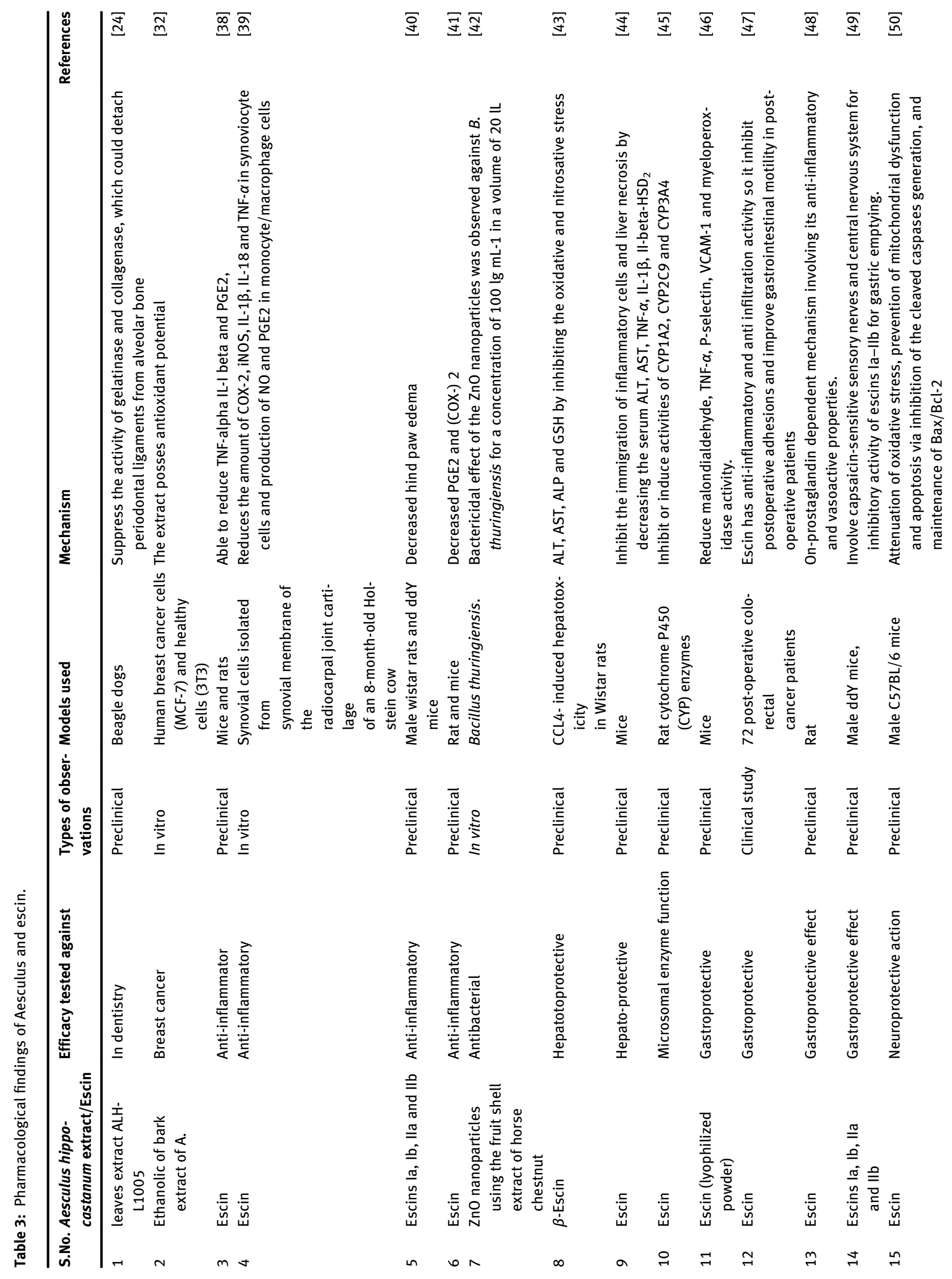




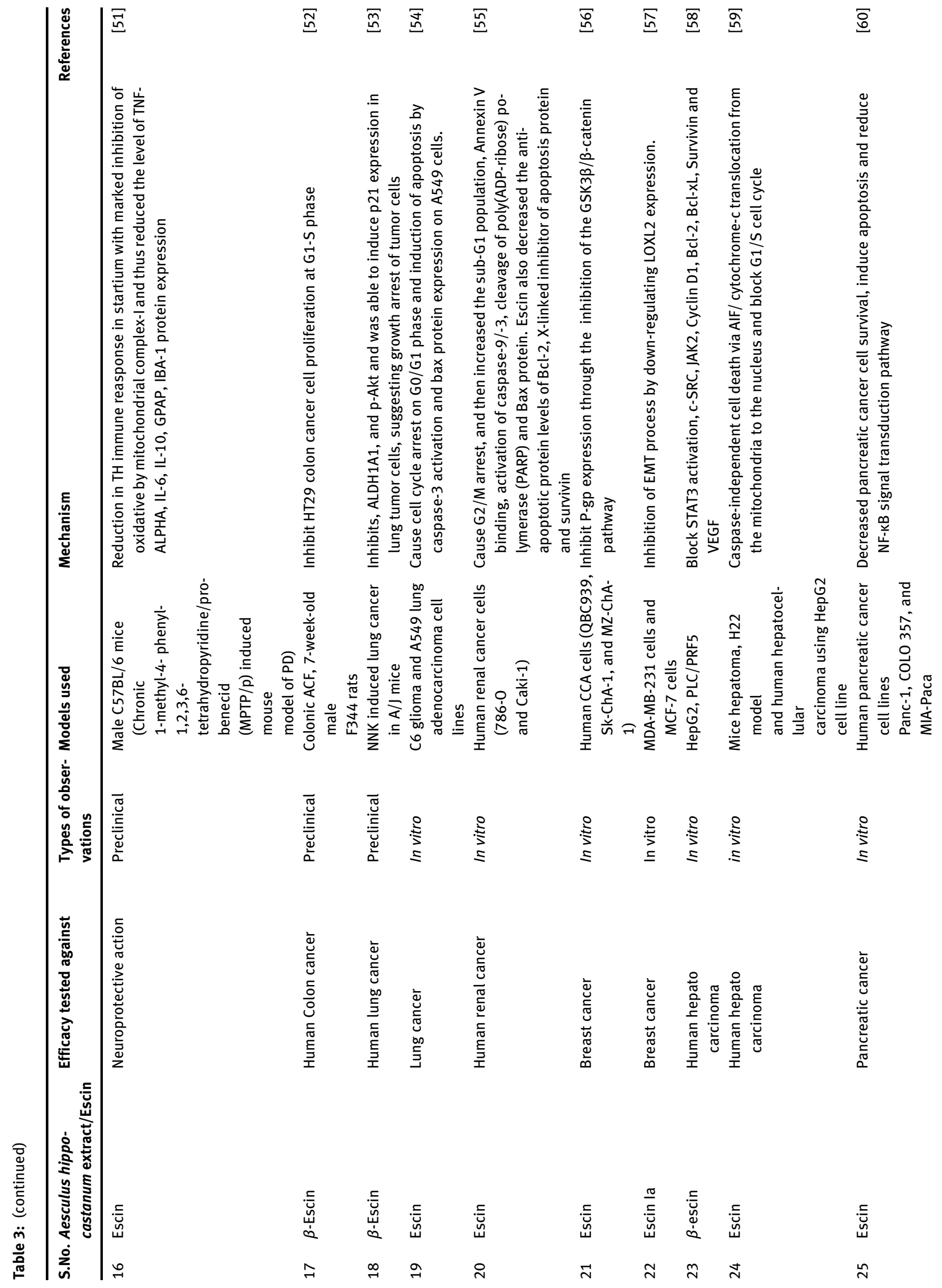




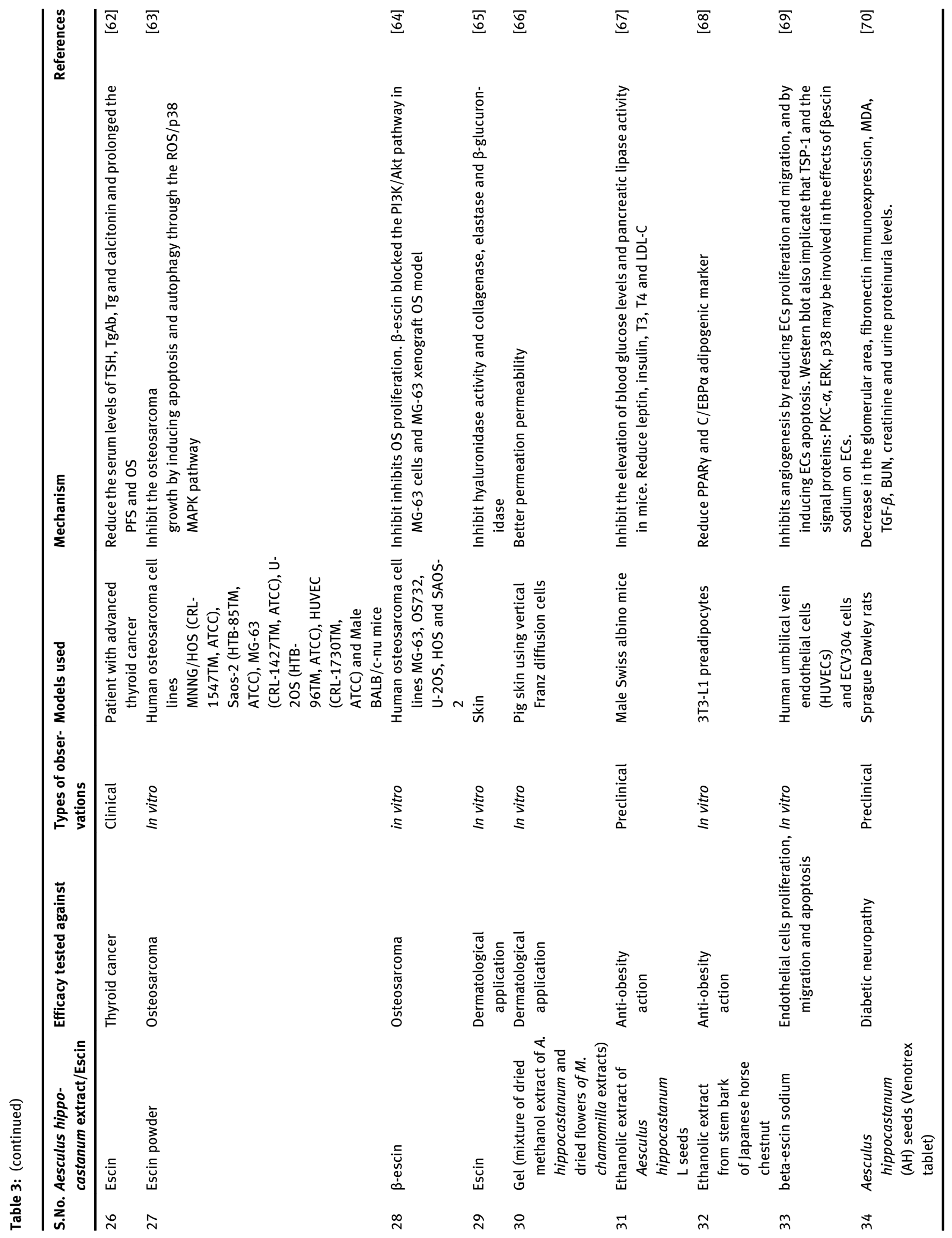


antiseptic, antioxidant, anti-pyretic, analgesic and antiaging agent [28], Further it is topically useful in cosmetic industry and in treatment of infections of ear, nose and throat regions [29]. While in other than pharmacological applications horse chestnut (A. hippocastanum) was used as a source of nonedible starch and timber [30, 31]. Evidences confirmed pharmacological applications in treatment of gastric ulcer [32], brain trauma, stroke, venous congestion, hemorrhoids, thrombo-phlebitis [33], cardiac vein insufficiency, burns, epidermis abrasion, skin inflammation and frost bite [34, 35, 74]. Further it causes the reduction of cellulite and hematoma, act as an astringent, for diarrhoea, in post-operative edema, in urolithiasis, and enhances oxidative defense system [36]. It also posses the anti-inflammatory, antiedemoatous [18], hypoglycemic, antithrombotic [33], anti-venotonic, antiedemigenic activity [37], and antibacterial activity towards the Staphylococcuses aureus, Escherichia coli, and Streptococcus mutans. Antibacterial activity is particularly against $E$. coli [38].

\section{Pharmacological findings}

Literature studies revealed Aesculus hippocastanum L. has many traditional uses but followings are specific Pharamacological activities which shown markedly significant results, detailed in Figure 1 and the finding from different researchers are tabulated in Table3.

\section{Anti-obesity effect}

Escin is a mixture of triterpene glycoside which is isolated from seeds of Aesculus hippocastanum. A study was made to investigate the anti-obesity activity of escin in mice fed with high fat diet for 5 weeks. After treatment with escin results showed the decrease level in leptin, FT level, increase HDL-C concentration but show no effect on LDL-C concentration [68], while in other study it has been found that the ethanolic extract of stem bark of the Japanese horse chestnut is able to inhibit the lipid accumulation in 3T3-L1 adipocytes. The result found that the JHC extract significantly decrease the PPARy and C/EBP $\alpha$ which are considered as most important adipogenic key markers, so JHC extract might be useful as anti-obesity agent [69].

\section{Effect on endothelial cells proliferation, migration and apoptosis}

Beta-escin was observed for the proliferation, migration and apoptosis in the human umbilical vein endothelial cells
(HUVECs) and ECV304 cells by sulforhodamine B (SRB) assay and result showed that Beta-escin sodium at the dose of 10, $20,40 \mu \mathrm{g} / \mathrm{mL}$ inhibit the endothelial cells proliferation and induced ECs apoptosis at dose of $40 \mu \mathrm{g} / \mathrm{mL}$. Cell migration was identified by the improved wound assay, while Western blot implicate that Beta-escin sodium increased TSP-1 expression, decreasing PKC- $\alpha$, phosphor-P38 (mitogenactivated protein kinase) and phosphor- ERK expression and involved in the effects of $\beta$-escin sodium on ECs [70].

\section{Effect on diabetic neuropathy}

A study was performed to describe the preventive effect of $A$. hippocastanum seed extract on oxidative stress and TGF-beta related diabetic nephropathy on streptozotocin induced diabetic rats. It has been found that escin, is responsible for preventing the negative effect of streptozotocin induced diabetic neuropathy by decreasing fibronectin in glomerular area, reduced immune expression, and reduced MDA, TGF-beta, creatinine, urine proteinuria level and improve the functional properties of kidney by preventing development of diabetic neuropathy but blood glucose level was unaltered [71].

\section{Control of environmental pollution}

A. hippocastanum is not only an ornamental tree but it is also an important biomonitor for the polluted environment. A study describes that $A$. hippocastanum tree is very useful for quantifying some heavy metals and toxic elements like cadmium, chromium, copper, lead, vanadium and uranium from urban areas of Plovdiv Town, Bulgaria with different anthropogenic impact. Aesculus hippocastanum leaves are effective and trustworthy plant species which helps in controlling the environmental pollution [72].

\section{Role in dentistry}

Preclinical research was carried out in beagle dogs to assess the effect of horse chestnut leaves extract ALHL1005 on periodontitis as a MMP inhibitor. Result showed that the ALH-L1005 horse chestnut leaves extract would be effective in periodontitis due to its ability to suppress the activity of gelatinase and collagenase in inflammation [24].

\section{Anti-inflammatory activity}

Research was carried out for evaluation of anti-inflammatory effect of escin, a triterpene saponin obtained 
from A. hippocastanum against carrageenan induced paw edema and histamine induced capillary permeability in rats using topical gel. Edema was evaluated in paraxylene induced ear swelling in mice and cotton pellet induced granuloma in rat and results describe the decreased level of TNF- $\alpha$ IL-I beta and PGE2. Further, results confirmed the reduction of enhanced vascular permeability at doses of $50 \mathrm{mg} / \mathrm{kg}$ and $200 \mathrm{mg} / \mathrm{kg}$ of escin. It reduces the hind paw edema induced by both Carrageenan and acetic acid in all doses [39]. Other experiment confirmed the anti inflammatory effect of escin in compared to ibuprofen and dexamethasone in synoviocyte model for osteoarthritis. The focus of this experiment was to reduce the level of COX-2, iNOS, IL$1 \beta$, IL-18, and TNF- $\alpha$ in synoviocyte cells and production of NO and PGE2 in monocyte/macrophage cells in osteoarthritis disorder and findings showed that, Escin had great ability of decreasing the production of COX-2, iNOS, IL-1 $\beta$, IL-18, and TNF- $\alpha$ in synoviocyte cells and production of NO and PGE2 in monocyte/macrophage cells and also reduce pain and inflammation in osteoarthritis [40]. Other anti-inflammatory study showed that escins Ia, Ib, IIa, IIb and desacylescins I and II are effective to treat acute inflammation in rat and mice model. $50-200 \mathrm{mg} / \mathrm{kg}$ dose of escins Ia, Ib, IIa, IIb is sufficient to inhibit the increase of vascular permeability while $200 \mathrm{mg} / \mathrm{kg}$ dose of escins Ia, Ib, IIa, IIb reduced the hind paw edema induced by carrageenin in rats, so it is confirmed that escin has anti-inflammatory property [41]. Further research was undertaken to evaluate the effects of it on oral administration on acute inflammation and intestinal mucosal injury in animal models. The effect on acute inflammation was observed by carrageenan-induced paw edema in rat and cecal ligation and puncture (CLP) was made to cause intestinal mucosal injury in the mouse model. Results revealed that oral administration of escin inhibited carrageenan-induced paw edema and decreases the production of prostaglandin E2 (PGE2) and cyclooxygenase- (COX-) 2. In CLP induced endotoxemic model escin showed the reduction in intestinal mucosal injury [42].

\section{Antibacterial activity}

Aesculus hippocastanum seeds was screened for its antibacterial properties and findings represent that the seeds possess antibacterial activity using various microbes like Staphylococcus aureus, Escherichia coli, and Streptococcus mutants and the reports showed more potent action against the E. coli specis in compared to others [38]. In another pharmacological screening, antimicrobial activity was performed by the formation of $\mathrm{ZnO}$ nanoparticles using the extract of the shells of Aesculus hippocastanum seeds of different concentrations and the bactericidal effect of $\mathrm{ZnO}$ nanoparticles was observed against $B$. thuringiensis [43].

\section{Hepatoprotective effect}

An investigation was performed to know the hepatoprotective role of escin in carbon tetrachloride $\left(\mathrm{CCl}_{4}\right)$ induced hepatotoxicity in rats and result showed that it is very effective to decrease the elevated marker enzymes like ALT, AST, ALP and GSH by inhibiting the oxidative and nitrosative stress [44]. Another study was carried out to investigate the protective effect of escin against hepatic injury induced by injecting the LPS. After treatment results explain that escin potentially inhibit the immigration of inflammatory cells and inhibit liver necrosis with reducing serum ALT, AST, TNF-alpha, IL-1beta, II-beta$\mathrm{HSD}_{2}$ expression in liver and up regulation of GR expression [45].

\section{Altered microsomal enzymes}

Findings from researchers reveal that escin could modify the effect on cytochrome $\mathrm{P} 450$ enzyme. A cocktail solution at a dose of $5 \mathrm{~mL} / \mathrm{kg}$, containing tolbutamide $(5 \mathrm{mg} / \mathrm{kg}$ ), phenacetin $(20 \mathrm{mg} / \mathrm{kg})$, chlorzoxazone $(20 \mathrm{mg} / \mathrm{kg})$ and midazolam $(10 \mathrm{mg} / \mathrm{kg})$ was given as oral administration to rats then the rats were treated with a single dose or multiple doses of intravenous escin via the caudal vein and results concluded that the single or multiple dose of escin can inhibit the CYP2C9 and CYP3A4 enzyme activity while induces the activities of CYP1A2 but has no inductive or inhibited effect on CYP2E1 [46].

\section{Gastro protective}

A gastro protective research was carried out to explain the effect of escin on gastrointestinal tract, and result showed that escin is capable to inhibit the gastric ulceration induce by indomethacin at the dose of $18 \mathrm{mg} / \mathrm{kg}$ by intragastric administration. Escin also protect the gastric tissue and decrease level of ulcer index and inhibit the neutrophil infiltration [47]. Other study assesses the gastroprotective activity of escin and results confirmed that escin is clinically well tolerated and has efficiency on improving the 
gastrointestinal motility in patients with colorectal cancer as well [48]. A research has been conducted to observe the anti-secretory and anti-ulcerogenic effect of escin in absolute ethanol induced gastric mucosal lesions in rat and results reveals that escin posses gastroprotective effect due to its anti-oxidant and anti-inflammatoy activity [49]. A study was made to confirm that saponin fraction from horse chestnuts and its principal saponins, escins Ia-IIb inhibited the gastric emptying in mice dose dependently either they are fed with a non-nutrient meal (1.5\% CMC-Na) or with nutrient meal (40\% glucose and milk) and 30\% ethanol [50].

\section{Neuroprotective}

The current study demonstrate that escin is potentially effective for Parkinson's disease due to its anti-inflammatory and antioxidant property. Experiments suggest that Oral treatment with escin significantly attenuated MPTP/p induced dopaminergic markers and useful as a neuroprotective agent. Neuroprevention of escin may be associated with the reduction of oxidative stress (increased nitrite and deplet NPSH levels), prevention of mitochondrial dysfunction and apoptosis via inhibition of the cleaved caspases generation, and maintenance of $\mathrm{Bax} / \mathrm{Bcl}-2$ ratio in MPTP/p model [51]. Other study reported that escin possess neuroprotection against chronic 1-methyl-4-phenyl-1,2,3,6tetrahydropyridine/probenecid (MPTP/p)-induced toxicity. Escin causes reduction in TH immune reasponse in startium with marked inhibition of oxidative by mitochondrial complex-I and thus reduced the level of TNF-ALPHA, IL-6, IL-10, GPAP, IBA-1 protein expression in rat model [52].

\section{Anticancer activity}

A number of studies indicated that extract of horse chestnut may possess significant cancer chemopreventive capacities.

\section{Effect on colon cancer}

Escin is evaluated for anticancer activity on azoxymethane-induced colonic aberrant crypt foci. In, in vivo studies beta-escin inhibits colon carcinogenesis in rats while in vitro analysis suggest that Beta-escin exhibit cytotoxic effect in colon cancer cell lines and results showed that Beta-escin significantly inhibit HT29 colon cancer cell proliferation at low concentration by induction of $\mathrm{p}^{2 \mathrm{WWAF} / \mathrm{CIP1}}$ and reduction of the level of $\mathrm{Cdk}_{2}$ and cyclin $\mathrm{A}$ and E composite, and causes cell cycle arresting at G1 phase and phosphorylation of ribosomes [53].

\section{Lung cancer}

Beta-escin is the major bioactive compound of Aesculus hipposactanum and proved as the potential chemotherapeutic agent. Beta-escin has ability to inhibit the lung adenoma and adenocarcinoma induced by tobacco carcinogen 4-(methyl-nitrosamino)-1-(3-pyridyl)-1-butanone (NNK) in female A/J mice and result showed that Beta-escin reduced the lung adenocarcinoma multiplicity and tumor size whether mice were received short- or long-term exposoure. Further, Beta-Escin inhibits ALDH1A1, and p-Akt and induce p21 expression in lung cancer cells, cause growth arrest of tumor cells and CSCs as one of the possible mechanism for the same [53]. Other study demonstrate that escin also inhibit glioma in A549 cell line in dose and time dependent manner. Escin induces apopotosis by caspase-3 activation and expression of bax protein and causes the cell cycle arrest in G0/G1 phase in cancer cell line. Apopotosis is occurs highly in A549 cell as compare to C6 glioma cells by mitochondrial cell death signalling pathway. So we can use escin as a potent antitumor agent [55].

\section{Human renal cancer}

A study was carried out to demonstrate the cytotoxic effects of escin on human renal cancer cells (786 O and Caki-1) by MTT assay and result explain that escin causes cell death or apoptosis in human renal cancer cells by inducing the intrinsic-mitochondrial apoptosis pathway and arrest G2/ $\mathrm{M}$ phase. Also increase the sub-G1 stage, annexin V binding, with activation of caspase protein, cleavage of poly adenosine diphosphate-ribose polymerase (PARP), bax protein and formation of reactive oxygen species (ROS). Escin reduces the anti-apoptotic protein levels of Bcl-2, Xlinked inhibitor of apoptosis protein [56].

\section{Breast cancer}

An observation was made for investigation of the antioxidant and antitumor activity of bark, seeds, leaves and flowers of A. hippocastanum and it was found that all the parts of A. hippocastanum extracts has significant antioxidant properties, but bark extract exhibit the highest potential due to its high phenolic content, also it is potentially effective to diminish the cell viability of MCF-7 cell line by about $70 \%$ [33]. In another research it was observed that escin suppress the metastasis of triple-negative breast 
cancer cells through inhibiting epithelial-mesenchymal transition. Furthermore, study also showed escin can reverse multidrug resistance through inhibition of the GSK3 $\beta / \beta$ - catenin pathway in cholangiocarcinoma cells [57]. Another study demonstrated the potential effect of escin Ia on triple negative breast cancer. Result of this study showed that escin Ia reduced the expression of LOXL2 mRNA and stimulate E-cadherin mRNA expression and prevented the EMT process of MDA-MB-231 cells and TNF- $\alpha$ /TGF- $\beta$-stimulated MCF-7 cell lines. Stimulated cell lines were transfected with LOXL2 or treated with hypoxia, and found escin Ia downregulated the level of LOXL2 level. In the TNBC xenograft mice model, the metastasis and EMT of MDA-MB-231 cells were suppressed by escin Ia and cause metastasis of TNBC via the inhibition of epithilail- mesenchymal transition by down regulation of LOXL2 expression [58].

\section{Hepatocellular carcinoma}

Many studies proven that escin is well tolerated and has potential ability against inflammatory diseases and cancers. A study was performed to investigate the hepatoprotective role of Beta-escin in hepatocellular carcimnoma (HCC). Results of this study confirm that escin inhibited both constitutive and interleukin-6-inducible STAT 3 activation in HCC cells and induced the expression of tyrosine phosphatase Src homology phosphatase 1, which is related with down-regulation of constitutive STAT 3 activation. Finally Beta-escin inhibited the proliferation and potentiated the apoptotic effects of paclitaxel and doxorubicin in HCC cell lines and confirmed it as a novel blocker of STAT 3 which may have potential in the suppression of proliferation [59]. A study was carried out to find the antitumor efficacy of escin on mice hepatocellular carcinoma in vivo and human hepatocellular carcinoma using HepG2 cell line in vitro and shows positive results, which confirms it's potentcy against hepatocellular carcinoma [61]. Escin cause caspase-independent cell death via AIF/cytochrome-c translocation from the mitochondria to the nucleus and block the G1/S cell cycle checkpoints. Escin also encourage the termination of treated HepG2 cells, possibly by a combination of mechanisms that includes the mitochondria-dependent apoptotic cascade encompassing a caspase-independent mode of cell death mediated via the translocation of AIF/cytochrome-c [60].

\section{Pancreatic cancer}

Escin is potentially able to decrease pancreatic cancer cell survival, reduce NF-kB signal transduction pathway, induced apoptosis and responsible for chemosensitization of pancreatic tumor cells. Chemosensitization of pancreatic cells arbitrate through the ability of escin to modify cellsignaling molecules i. e. cell proliferating proteins, such as cyclin D and members of the NF- $\kappa B$ signaling pathways. It is believed that cisplatin and gemcitabine reduces the cell survival rate in a dose-dependent manner. Researcher confirmed the combined effect of both these drugs and found cisplatin have a synergistic effect on pancreatic cell survival, while escin combined with gemcitabine showed only additive effect. High concentrations of escin induced apoptosis and decreased NF-kB-related proteins and cyclin $D$ expression. So we can said that escin has significant role in the reduction of pancreatic cell survival [62].

\section{Thyroid cancer}

A clinical research was made to prove the efficacy of escin that it may reduce the thyroid cancer cells and results reveals that, escin significantly reduced the serum levels of $\mathrm{TSH}, \mathrm{TgAb}, \mathrm{Tg}$ and calcitonin while prolonged the PFS (progression-free survival) and OS (overall survival) at the dose of $0.6 \mathrm{mg} / \mathrm{kg} /$ day intravenously for patients with advanced thyroid cancer. Escin is well tolerated and safe agent for thyroid cancer [63].

\section{Osteosarcoma}

Many clinical studies prove that escin is a potential chemotherapeutic agent. A research conducted to investigate the therapeutic effect of escin on osteosarcoma in an orthotopic model and result confirmed that escin is able to inhibit the osteosarcoma proliferation, induce apoptosis and autophagy.Apoptosis was confirmed by increased expression of caspase-related proteins and the formation of apoptotic bodies while autophagy was identified by the increased level of LC3, ATG5, ATG12, Beclin expression and autophagosome formation. Escin activates the A p38 mitogen-activated protein kinases (MAPKs) and reactive oxygen species (ROS).A p38 MAPK inhibitor partially regulate the autophagy and apoptosis induce by escin, but ROS scavenger showed inhibitory effect. Finally, study confirmed escin potentially reduced the osteosarcoma via inducing autophagy and apoptosis by the activation of the ROS/p38 MAPK signalling pathway [64]. In other study it was confirmed that Beta-escin is effective to inhibit the cell proliferation of human OS cells in vitro and in vivo by blocking the PI3K/Akt signalling pathway in MG-63 cells. Beta-escin induces activation of caspase-3, caspase- 8 and caspase- 9 in MG- 63 cells and effective against MG-63, OS732, U-2OS, HOS and SAOS-2 cell proliferation in time and dose dependent manner. The results showed that 
Beta-escin significantly act as anti-proliferative and proapoptotic agent in an established OS xenograft model. $\beta$ esin produce synergistic effect with other chemotherapeutic agents [65].

\section{Dermatological application}

According to Wilkinson and Brown, escin inhibits hyaluronidase enzyme, however, decrease level of hyaluronidase leads to be insufficient to produce powerful venotonic effect while the effect of extract of A. hippocastanum on the microvasculature was more in compared to only escin, it may be due to presence of other enzymes like collagenase, elastase and $\beta$-glucuronidase that's why extracts of A. hippocastanum were distinctly more efficient than escin alone. In other study the gel containing the mixture of $A$. hippocastanum and $M$. chamomilla extracts imports better permeability and stability for topical delivery in compared to the gels containing barely escin or $A$. hippocastanum extract alone [66, 67].

\section{Conclusions}

From the literature reports, it is confirmed that the active components of horse chestnut tree are responsible for the pharmacological effects. The major component of A. hippocastanum is escin, esculetin, esculin, scopoletin and fraxetin out of which some are reported for their marked efficacy like escin, useful for their anti-cancer efficacy against various cancers [54, 55, 57, 72], whereas other secondary metabolites are useful for protective effect either alone or in extract as combination. The recent research indicates anti-inflammatory and antibacterial efficacy of escin $[40,39]$. So further researches has to be carried out on other active components to find out some novel medicinal applications of these existing herbal drug, Herbal medicines are safe and better efficacy then synthetic products. Plants are being considered as a valuable source of natural medical products which are helpful in preventing and treating various diseases either by enhancing antioxidant activity, bacterial growth inhibition or by modulation of genetic pathways. Today medicinal herbs are still viewed as essential source of biomolecule for the making of new medicines.The therapeutic appliance of Aesculus is due to the presence of important bioactive, some are summarized in this review, so we found out this plant has wider medicinal applications against various conditions including environmental and dental condition as explained by some researchers, still further research is needed for newly derived phytoconstituents and their application in multidisciplinary area.

Acknowledgments: The authors offer their sincere thanks, Dean R\&D, Integral University for providing technical support and assigning communication reference no: IU/ R\&D/2018-MCN000445, for further communication.

Research funding: None declared.

Author contributions: All authors have accepted responsibility for the entire content of this manuscript and approved its submission.

Competing interests: Authors state no conflict of interest.

\section{References}

1. Woo CSJ, Lau JSH, El-Nezami H. Herbal medicine: toxicity and recent trends in assessing their potential toxic effects. Adv Botanical Research 2012;62:365-84.

2. Karlinski L, Jagodzinski AM, Leski T, Butkiewicz P, Brosz M, Rudawska $M$. Fine root parameters and mycorrhizal colonization of horse chestnut trees (Aesculus hippocastanum L.) in urban and rural environments. Landscape Urban Plan 2014;127:154-63.

3. Simon $P$, Lena $M$. Radial growth response of horse chestnut (Aesculus hippocastanum L.) trees to climate in Ljubljana. Urban Urban Green 2016:111-6. https://doi.org/10.1016/j.ufug.2016. 05.013.

4. Kosalec I, Cvek J, Tomic S. Contaminants of medicinal herbs and herbal products. Arh Hig Rada Toksikol 2009;60:485-501.

5. Zong A, Cao H, Wang F. Anticancer polysaccharides from natural resources: a review of recent research. Carbohydr Polym 2012; 90:1395-410.

6. Efferth T, Koch E. Complex interactions between phytochemicals; The multi-target therapeutic concept of phytotherapy. Curr Drug Targets 2011;12:122-32.

7. Kapusta I, Janda B, Szajwaj B, Stochmal A, Piacente S, Pizza C, et al. Flavonoids in horse chestnut (Aesculus hippocastanum) seeds and powdered waste water byproducts. J Agric. Food Chem 2007;55:8485-90.

8. Calic D, Bohanec B, Devrnja N, Milojevic J, Tubic L, Kostic I, et al. Impact of abscisic acid in overcoming the problem of albinism in horse chestnut androgenic embryos. Trees 2013;27:755-62.

9. Brus R. Drevesne vrste na slovenskem (tree species on Slovenian area; in Slovenian). Mladinska zalozba Ljubljana, slovenia, 2004.

10. Dragosavac DC, Korac SZ, Fodulovic KS, Radojevic L, Vinterhalter B. Determination of escin content in androgenic embryos and hairy root culture of Aesculus hippocastanum. Pharm Biol 2010;48:563-7.

11. Wu XJ, Cui XY, Tian LT, Gao G, Guan X, Gu JK. Pharmacokinetics of escin la in rats after intravenous administration. J Ethnopharmacol 2014;156:125-9.

12. Deschka GN, Dimic. Cameraria ohridella n. sp. aus mazedonien, jugoslawien (lepidoptera: lithocolletidae). J Acta Entomol Jugosl 1986;22:11-23.

13. Grabenweger G, Grill R. On the place of origin of Cameraria ohridella deschka \& dimic (lepidoptera: gracillariidae). J Beitr Entomofaun 2000;1:9-17. 
14. Baraniak E, Walczak U, Zduniak P. Appearance and migration of the horse-chestnut leafminer Cameraria ohridella in relation to city size and leaf-raking, using the example of two cities in Western Poland. J Pest Sci 2005;78:145-9.

15. Thalmann C, Freise J, Heitland W, Bacher S. Effects of defoliation by horse chestnut leafminer (Cameraria ohridella) on reproduction in Aesculus hippocastanum. J Trees 2003;17:383-8.

16. Łyżwa JM, Kaca W, Żarnowiec P. Biological activity of wild isolates of entomopathogenic nematodes to horse- chestnut leaf miner (Cameraria ohridella). Pol J Environ Stud 2015;24:1181-4.

17. Zhang Z, Li S, Lian XY. An overview of genus Aesculus l.: ethnobotany, phytochemistry, and pharmacological activities. Pharm Crops 2010;1:24-51.

18. Sirtori CR. Escin: pharmacology, pharmacokinetics and therapeutic profile. J Pharmacol Res 2001;44:183-93.

19. Paterska M, Bandurska H, Wystouch J, Glura MM, Molinski K. Chemical composition of horse-chestnut (Aesculus) leaves and their susceptibility to chestnut leaf miner Cameraria ohridella deschka \& dimic. J Acta Physiol Plant 2017;39:105.

20. Duke JA. CRC handbook of medicinal herbs. Boca Raton: CRC Press; 1985.

21. Robbers JE, Tyler VE. Tyler's herbs of choice: the therapeutic use of phytomedicinals. New York, NY: Haworth Herbal Press; 1999.

22. Newall CA, Anderson LA, Phillipson JD. Herbal medicines: a guide for health-care professionals. London: Pharmaceutical Press; 1996.

23. Makuch MD, Matlawska I. Coumarins in horse chestnut flowers: isolation and quantification by uplc method. J Acta Poloniae Pharm Drug Res 2013;70:517-22.

24. Kim SE, Kim TH, Park SA, Kim WT, Park YW, Ahn JS, et al. Efficacy of horse chestnut leaf extract ALH-L1005 as a matrix metalloproteinase inhibitor in ligature-induced periodontitis in canine model. J Vet Sci 2017;18:245-51.

25. Kedzierskia B, Kocha WK, Widelskia J, Gtowniak K. Impact of harvest time of Aesculus hippocastanum seeds on the composition, antioxidant capacity and total phenolic content. Ind Crops Prod 2016;86:68-72.

26. Srijayanta S, Raman A, Goodwin BLA. Comparative study of the constituents of Aesculus hippocastanum and Aesculus indica. J Med. Food 1999;2:45-50.

27. Makuch MD, Matlawska I. Flavonoids from the flowers of Aesculus hippocastanum. Acta Poloniae Pharm Drug Res 2011; 68:403-8.

28. Patlolla JMR, Rao CV. Anti-inflammatory and anti-cancer properties of $\beta$-escin, a triterpene saponin. J Curr Pharmacol Rep 2015;1:170-8.

29. Marton G, Bakan A. Research and development of an integrated and wastefree utilization of horse chestnut (Aesculus hippocastanum) seeds. J Bioresour Technol 1995; 54:197-200.

30. Castano J, Llamazares SR, Contreras K, Carrasco C, Pozo C, Bouza R, et al. Horse chestnut (Aesculus hippocastanum L.) starch: basic physico-chemical characteristics and use as thermoplastic material. Carbohydr Polym 2014;112:677-85.

31. Jekkel Z, Gyulai G, Kiss J, Kiss E, Heszky LE. Cryopreservation of horse-chestnut (Aesculus hippocastanum L.) somatic embryos using three different freezing methods. Plant Cell Tiss Org 1998;52:193-7.

32. Roy A, Geetha RV, Lakshmi T. Evaluation of the antimycotic activity of aqueous and ethanolic extracts of Aesculus hippocastanum-An in vitro study. Int J Drug Dev Res 2011;3:335-8.
33. Celep AGS, Yilmaz S, Coruh N. Antioxidant capacity and cytotoxicity of Aesculus hippocastanum on breast cancer MCF-7 cells. J Food Drug Anal 2012;20:692-8.

34. Bombardelli E, Morazzoni P, Griffini A. Aesculus hippocastanum L. J Fitoterapia 1996;67:483-511.

35. Hagers H, Hansel R, Keller K, Rimler H, Schneider G, Drogen AD. Hagers Handbuch der Pharmazeutischen Praxis. Berlin: SpringerVerlag; 1992.

36. Stajner D, Popovic BM, Calic D, Stajner M. Comparative study of antioxidant status in androgenic embryos of Aesculus hippocastanum and Aesculus flava. Sci World J 2014;11:1-8.

37. Braga PC, Marabini L, Wang YY, Lattuada N, Calo R, Bertelli A, et al. Characterisation of the antioxidant effects of Aesculus hippocastanum L. bark extract on the basis of radical scavenging activity, the chemiluminescence of human neutrophil bursts and lipoperoxidation assay. Eur Rev Med Pharmacol Sci 2012;16:1-9.

38. Takahashi T, Tsurunaga Y, Schmidt WF, Yoshino K. Functional evaluation of horse chestnut seed and its application in the production of compounded paper for effective utilization of an untapped resource. J Wood Sci 2017;63:484-95.

39. Qi ZS, Qiang XUS, Jing C, Lu CX, Ying Z, Ping ZW, et al. Antiinflammatory effect of external use of escin on cutaneous inflammation: possible involvement of glucocorticoids receptor. Chin J Nat Med 2018;16:105-12.

40. Maghsoudi H, Hallajzadeh J, Rezaeipour M. Evaluation of the effect of polyphenol of escin compared with ibuprofen and dexamethasone in synoviocyte model for osteoarthritis: an in vitro study. J Clin Rheumatol 2018;37: 2471-8.

41. Mastuda H, Li Y, Murakami T, Ninomiya K, Yamahara J, Yoshikawa M. Effects of aescins la, Ib, Ila and II b, from horse chestnut, the seeds of Aesculus hippocastanum L., on acute inflammation in animals. Biol Pharm Bull 1997;20:1092-5.

42. Li M, Lu C, Zhang L, Zhang J, Du Y, Duan S, et al. Oral administration of escin inhibits acute inflammation and reduces intestinal mucosal injury in animal models. Evid Based Complement Alternat Med 2015;2015:1-9.

43. Colak H, Karakose E, Duman F. High optoelectronic and antimicrobial performances of green synthesized $\mathrm{ZnO}$ nanoparticles using Aesculus hippocastanum. Environ Chem Lett 2017;15:547-52.

44. Singh H, Sidhu S, Chopra K, Khan MU. The novel role of b-escin in attenuating $\mathrm{CCl} 4$-induced hepatotoxicity in rats. Pharm Biol 2017;55:749-57.

45. Jiang N, Xin W, Wang T, Zhang L, Fan H, Du Y, et al. Protective effect of aescin from the seeds of Aesculus hippocastanum on liver injury induced by endotoxin in mice. Phytomedicine 2011;18: 1276-84.

46. Huang Y, Zheng SL, Zhu HY, Xu ZS, Xu RA. Effects of escin on cytochrome P450 enzymes in rats. Ethnopharmacology 2014;151: 583-90.

47. Wang T, Zhao S, Wang Y, Yang Y, Yao L, Chu L, et al. Protective effects of escin against indomethacin-induced gastric ulcer in mice. Toxicol Mech Methods 2014;24:560-6.

48. Xie Q, Zong X, Ge B, Wang S, Ji J, Ye Y, et al. Pilot postoperative ileus study of escin in cancer patients after colorectal surgery. World J Surg 2009;33:348-54. 
49. Marhuenda E, Lastra ADLL, Martin MJ. Antisecretory and gastroprotecive effects of aescine in rats. Gen Pharm 1994;25: 1213-9.

50. Matsuda H, Li Y, Murakami T, Yamahara J, Yoshikawa M. Effects of escins la, lb, Ila, and Ilb from horse chestnuts on gastric emptying in mice. Eur J Pharmacol 1999;368:237-43.

51. Selvakumar GP, Manivasagam T, Rekha KR, Jayaraj RL, Elangovan N. Escin a Novel triterpene, mitigates chronic MPTP/Pinduced dopaminergic toxicity by attenuating mitochondrial dysfunction, oxidative stress, and apoptosis. J Mol Neurosc 2014; 55:184-97.

52. Selvakumar GP, Janakiraman U, Essa MM, Thenmozhi AJ, Manivasagam T. Escin attenuates behavioral impairments, oxidative stress and inflammation in a chronic MPTP/probenecid mouse model of Parkinson's disease. Brain Res 2014; 1585:23-36.

53. Patlolla JMR, Raju J, Swamy MV, Rao CV. $\beta$-escin inhibits colonic aberrabt crypt foci formation in rats and regulates the cell cycle growth by inducing $\mathrm{p}^{21 \mathrm{WAF} / \mathrm{CP} 1}$ in colon cancer cells. Mol Cancer Ther 2006;5:1459-66.

54. Patlolla JMR, Qian L, Biddick L, Zhang Y, Desai D, Amin S, et al. $\beta$-escin inhibits NNK-induced lung adenocarcinoma and ALDH1A1and RhoA/Rock expression in A/J mice and growth of H460 human lung cancer cells. Cancer Prev Res 2013;5: 1140-9.

55. Ciftci GA, Iscan A, Kutlu M. Escin reduces cell proliferation and induces apoptosis on glioma and lung adenocarcinoma cell lines. Cytotechnology 2015;67:893-904.

56. Yuan SY, Cheng CL, Wang SS, Ho HC, Chiu KY, Chen CS, et al. Escin induces apoptosis in human renal cancer cells through G2/M arrest and reactive oxygen species-modulated mitochondrial pathways. Oncol Rep 2017;37:1002-10.

57. Huang GL, Shen DY, Cai CF, Zhang QY, Ren HY, Chen QX. Beta escin reverses multidrug resistance through inhibition of the GSK3beta/beta-catenin pathway in cholangiocarcinoma. World J Gastroenterol 2015;21:1148-57.

58. Wang Y, Xu X, Zhao P, Tong B, Wei Z, Dai Y. Escin la suppresses the metastasis of triple-negative breast cancer by inhibiting epithelial-mesenchymal transition via down-regulating LOXL2 expression. Oncotarget 2016;7:23684-99.

59. Tan SML, Li F, Rajendran P, Kumar AP, Hui KM, Sethi G. Identification of $\beta$-escin as a novel inhibitor of signal transducer and activator of transcription 3/Janus-activated kinase 2 signaling pathway that suppresses proliferation and induces apoptosis in human hepatocellular carcinoma cells. J Pharmacol Exp Ther 2010;334:285-93.

60. Zhou XY, Fu FH, Li Z, Dong QJ, He J, Wang CH. Escin, a natural mixture of triterpene saponins, exhibits antitumor activity against hepatocellular carcinoma. Planta Med 2009;75:1580-5.
61. Liu A, Shen Y, Du Y, Chen J, Pei F, Fu W, et al. Esculin prevents lipopolysaccharide/D-galactosamine-induced acute liver injury in mice. Microbial Pathog 2018;125:418-22.

62. Rimmon A, Vexler A, Berkovich L, Earon G, Ron I, Ari SL. Escin chemosensitizes human pancreatic cancer cells and inhibits the nuclear factor-kappa b signaling pathway. Biochem Res Int 2013: 1-9. https://doi.org/10.1155/2013/251752.

63. Mei JU, Zhang MJ, Wang YY, Liu YH. The positive clinical therapeutically effects of escin on advanced thyroid cancer. Cancer Med 2017;6:937-43.

64. Zhu J, Yu W, Liu B, Wang Y, Shao J, Wang J, et al. Escin induces caspase-dependent apoptosis and autophagy through the ROS/ p38 MAPK signaling pathway in human osteosarcoma cells in vitro and in vivo. Cell Death Dis 2017;8. https://doi.org/10. 1038/cddis.2017.488.

65. Zhu M, Ying J, Lin C, Wang Y, Huang K, Zhou Y, et al. Beta-escin inhibits the proliferation of osteosarcoma cells via blocking the PI3K/Akt pathway. RSC Adv 2018;8:29637-44.

66. Wilkinson JA, Brown AMG. Horse chestnut-Aesculus hippocastanum: potential applications in cosmetic skin-care products. Int J Cosmetic Sci 1999;21:437-47.

67. Ozkan EE, Mesut B, Polat, A, Tan N. In vitro skin permeation of escin in the new gel formulation of Aesculus hippocastanum (Horse Chestnut). J Fac Pharm Istanbul İstanbul Ecz Fak Derg 2016;46:79-88.

68. Avci G, Kucukkurt I, Akkol EK, Yesilada E. Effects of escin mixture from the seeds of Aesculus hippocastanum on obesity in mice fed a high fat diet. Pharm Biol 2010;48:247-52.

69. Nam H, Kim JK, Jung H, Suh JG. Anti-obesity effects of the stem bark of Japanese horse chestnut (Aesculus turbinate) in 3T3-L1 preadipocytes. Food Sci Biotechnol 2014;23:289-92.

70. Wang XH, Xu B, Liu JT, Cui JR. Effect of $\beta$-escin sodium on endothelial cells proliferation, migration and apoptosis. Vasc Pharmacol 2008;49:158-65.

71. Elmas 0, Erbasb 0, Yigitturk G. The efficacy of Aesculus hippocastanum seeds on diabetic nephropathy in a streptozotocin-induced diabetic rat model. Biomed Pharmacother 2016;83:392-6.

72. Petrova S, Yurukova L, Velcheva I. Horse chestnut (Aesculus hippocastanum L.) as a biomonitor of air pollution in the town of Plovdiv (Bulgaria). J Biosci Biotech 2012;1:241-7.

73. Şeremet OC, Bărbuceanu FL, Ionică FE, Margină DM, GuŢu CM, Olaru OT, et al. Oral toxicity study of certain plant extracts containing pyrrolizidine alkaloids. Rom J Morphol Embryol. 2016; 57:1017-23.

74. Margină D, Olaru OT, Ilie M, Grădinaru D, Guțu C, Voicu S, et al. Assessment of the potential health benefits of certain total extracts from Vitis vinifera, Aesculus hyppocastanum and Curcuma longa. Exp Ther Med 2015;10:1681-8. 